\title{
Use of serum bilirubin/albumin ratio for early prediction of bilirubin induced neurological dysfunction
}

\author{
Dalia Mosallam ${ }^{1,2^{*}}$ (D) Reem N. Said ${ }^{1}$, Marwa A. Abd Elsamad ${ }^{1}$ and Nada M. Abdelfatah ${ }^{1}$
}

\begin{abstract}
Background: Kernicterus or bilirubin encephalopathy is a preventable cause of handicap, still occurs in our country. The aim of the current study was to assess the role of bilirubin/albumin ratio in improving the morbidity of the cases with unconjugated hyperbilirubinemia and to estimate of the cutoff value for B/A ratio for prevention and early management of bilirubin-induced neurological dysfunction.

Results: The mean gestational age was $37.1 \pm 2.11$ weeks; the mean age of onset of jaundice was $2.36 \pm 1.04$ days; the mean level of total bilirubin was $26.14 \pm 7.36 \mathrm{mg} / \mathrm{dl}$. At chosen cutoff value of bilirubin albumin ratio (B/A) 6.68, sensitivity was $82 \%$ while specificity was $64 \%$ and accuracy was $95 \%$.

Conclusion: Bilirubin encephalopathy still occurs in significant number in our country though it is a preventable cause of handicapping. TSB is a sensitive but not a specific indicator of $A B E, B / A$ ratio is more specific indicator of the neurologic outcome and should be utilized in the decision of early intervention.
\end{abstract}

Keywords: Hyperbilirubinemia, Bilirubin/albumin ratio, Bilirubin encephalopathy

\section{Background}

Neonatal hyperbilirubinemia is a common problem. Approximately $60-70 \%$ of term and $\sim 80 \%$ of preterm infants develop jaundice in the first week of life [10]. Neonatal jaundice if inappropriately managed may result in significant bilirubin-induced mortality and disability [20, 21].

Jaundice due to either indirect (unconjugated) or direct (conjugated) bilirubin within the first $24 \mathrm{~h}$ of life should be taken seriously. Early identification and proper management are needed to prevent the serious neurological complications associated with it [3, 27]

Although $99.9 \%$ of unconjugated bilirubin in the circulation is bound to albumin, a relatively small fraction (only less than $0.1 \%$ ) remains unbound (free bilirubin) and it can go into the brain across an intact blood-brain barrier. According to the experimental studies, the concentration of free bilirubin is believed to dictate the biologic effect on jaundiced newborns, including its neurotoxicity [11].

* Correspondence: daliamosalam@hotmail.com

${ }^{1}$ Faculty of Medicine, Cairo University, Cairo, Egypt

${ }^{2}$ Dokki, Egypt

Springer Open
In most infants, unconjugated hyperbilirubinemia reflects a normal transitional phenomenon. However, in some infants, entry of unconjugated bilirubin into the brain can cause both short-term and long-term neurological dysfunction (bilirubin encephalopathy). In this case, unconjugated hyperbilirubinemia is potentially harmful for the central nervous system and may cause severe and permanent neurological sequelae that is defined as bilirubin-induced neurological dysfunction (BIND) [5].

Bilirubin-induced neurologic dysfunction (BIND) is the term applied to the spectrum of neurologic abnormalities associated with hyperbilirubinemia. It can be further divided into characteristic signs and symptoms that appear in the early stages (acute) and those that evolve over a prolonged period (chronic) [12].

The pathogenesis of BIND is multifactorial and includes interaction between the level of unconjugated bilirubin, free bilirubin, bilirubin bound to albumin, bilirubin passed through brain-blood barrier and nerve damage [15].

Kernicterus, or bilirubin encephalopathy, is a condition caused by bilirubin toxicity to the basal ganglia and 
various brain stem nuclei. Surviving infants usually develop a severe form of athetoid cerebral palsy, hearing loss, dental dysplasia, paralysis of upward gaze and, less often, intellectual, and other handicaps [1].

It could be also presented in the form of subtle neurodevelopmental delay or learning disabilities without classical findings of kernicterus that, after careful evaluation, appears to be due to bilirubin neurotoxicity [25]. The susceptibility to the neurotoxic effects of bilirubin varies according to cell type, brain maturity, and brain metabolism. Also, the concentration of bilirubin in the brain and the duration of exposure to bilirubin are important determinants of the neurotoxic effects of bilirubin, whereas the correlation between the serum bilirubin concentration and bilirubin encephalopathy is poor in infants without hemolysis [16].

BIND score is a scoring system, in which characteristics of mental state, muscle tone, and cry are grouped into three levels of increasing abnormality: stage IA, minimal signs; stage IB, progressive but reversible with treatment; stage II, advanced and largely irreversible, but may be significantly decreased by treatment [16]. There is also a modified BIND score (BIND-M) [23].

Indirect (unbound) bilirubin concentration is a better predictor of brain uptake and toxicity of bilirubin than TSB [26]. Free bilirubin (Bf) crosses the blood-brain barrier and exhibits neurotoxicity. In accordance, Bf is thought to predict bilirubin neurotoxicity more reliably than the total serum bilirubin (TSB), as assessed by clinical and electrophysiological parameters, i.e., neurodevelopmental outcome and maturation of automated brain stem responses, respectively [29].

There is presently no method available for measuring free bilirubin concentrations accurately in plasma or serum; therefore, adjunct measurements of albumin concentration and bilirubin albumin ratio may provide more insight into the likelihood of bilirubin-induced encephalopathy [14]. The B/A ratio is considered a surrogate parameter for free bilirubin and an interesting additional parameter in the management of hyperbilirubinemia [4, 20, 21].

Retrospective data have favored an additional role for high $\mathrm{B} / \mathrm{A}$ ratios as risk factors for bilirubin-induced neurotoxicity and only limited data exist regarding B/A ratios in the management and neurodevelopmental outcome of preterm infants with unconjugated hyperbilirubinemia [24].

\section{Methods}

This prospective cohort study was performed over a period of 6 months from January 2016 to June 2016 on neonates admitted to the NICU department, at Abuelrish Pediatric Hospital with severe hyperbilirubinemia reached critical level of phototherapy or exchange transfusion according to the American Academy of Pediatrics guidelines. The current study included 100 newborn infants classified into 2 groups. Group (1) included 50 neonates with indirect hyperbilirubinemia without neurological manifestations. Group (2) included 50 neonates with indirect hyperbilirubinemia with neurological manifestations.

Inclusion criteria included infants diagnosed by pediatrician as icteric requiring admission in neonatal ward for treatment, unconjugated hyperbilirubinemia developed at 1st week of age.

Exclusion criteria included infants with hydrops fetalis, congenital nephritic syndrome, and other diseases that mimic BIND e.g. convulsions due to intracranial hemorrhage etc. as well as death due to other reasons will be excluded.

All the cases were subjected to the following: (1) Clinical Evaluation: thorough history taking including prenatal history (maternal illness, PROM, maternal blood group and Rh, maternal drugs, fever, history of other siblings with jaundice), natal history (mode of delivery, resuscitation), and postnatal history (gestational age, gender, weight, type of jaundice, age at admission). (2) Full clinical examination including the following: general examination: vital signs, anthropometric measures, presence of cephalohematoma, apparent congenital anomalies; systemic examination: cardiac, abdominal, chest, neurological examination and assessment of neonatal reflexes.

Modified bilirubin-induced neurological dysfunction (BIND) score was done on admission for the patients who were presenting with neurological manifestations and was used to assess the severity of $\mathrm{ABE}$ through examining the mental state, muscle tone, and cry pattern (Table 1).

\section{Laboratory workup}

A. Serum bilirubin and serum albumin on admission before starting any treatment.

B. Type of jaundice was assessed using blood group of the baby and the mother, reticulocytic count and Coombs test.

C. Hemoglobin and hematocrit level was recorded.

D. Serum bilirubin albumin ratio was calculated.

\section{Treatment implemented}

Whether exchange transfusion, intensive or conventional phototherapy was recorded.

\section{Sample size}

Sample size was calculated to determine the minimum proper sample size. Sample size calculation was done using StatCalc, Epi Info version 7 for MS Windows, Centers for Disease Control and prevention (CDC), USA (Table 2). 
Table 1 Modified bilirubin-induced neurological dysfunction (BIND) score

\begin{tabular}{|c|c|c|c|}
\hline Clinical sign & Score & Severity & Date/time \\
\hline \multicolumn{4}{|l|}{ Mental status } \\
\hline Normal & 0 & None & \\
\hline $\begin{array}{l}\text { Sleepy but arousable } \\
\text { Decreased feeding }\end{array}$ & 1 & Mild & \\
\hline $\begin{array}{l}\text { Lethargy } \\
\text { Poor suck and/or } \\
\text { Irritable/jittery with short-term strong suck }\end{array}$ & 2 & Moderate & \\
\hline $\begin{array}{l}\text { Semi-coma } \\
\text { Apnea } \\
\text { Seizures } \\
\text { Coma }\end{array}$ & 3 & Severe & \\
\hline \multicolumn{4}{|l|}{ Muscle tone } \\
\hline Normal & 0 & None & \\
\hline Persistent mild hypotonia & 1 & Mild & \\
\hline $\begin{array}{l}\text { Moderate hypotonia } \\
\text { Moderate hypertonia } \\
\text { Increasing arching of neck and trunk on } \\
\text { stimulation without spasms of arms and legs and } \\
\text { without trismus }\end{array}$ & 2 & Moderate & \\
\hline $\begin{array}{l}\text { Persistent retrocolis } \\
\text { Opisthotonus } \\
\text { Crossing or scissoring of arms or legs but } \\
\text { without spasms of arms and legs and } \\
\text { without trismus }\end{array}$ & 3 & Severe & \\
\hline \multicolumn{4}{|l|}{ Cry pattern } \\
\hline Normal & 0 & None & \\
\hline High pitched & 1 & Mild & \\
\hline Shrill & 2 & Moderate & \\
\hline $\begin{array}{l}\text { Inconsolable crying or } \\
\text { Cry weak or absent in child with previous } \\
\text { history of high pitched or shrill cry }\end{array}$ & 3 & Severe & \\
\hline \multicolumn{4}{|l|}{ Occulomotor or eye movements } \\
\hline Normal & 0 & None, mild & \\
\hline $\begin{array}{l}\text { Sun-setting } \\
\text { Paralysis of upward gaze }\end{array}$ & 3 & Severe & \\
\hline Total ABE score & & & \\
\hline
\end{tabular}

Radmacher et al. [23]

\section{Statistical methods}

Data were coded and entered using the statistical package SPSS (Statistical Package for the Social Sciences) version 23. Data was summarized using mean, standard deviation, median, minimum, and maximum in quantitative data and using frequency (count) and relative frequency (percentage) for categorical data. ROC curve was constructed with area under curve analysis performed to

Table 2 Sample size

\begin{tabular}{ll}
\hline Sample size & \\
\hline Group 1 & 14 \\
Group 2 & 14 \\
Total & 28 \\
\hline
\end{tabular}

detect best cutoff value of bilirubin and B/A ratio for detection of neurological dysfunction. $P$ values less than 0.05 were considered as statistically significant.

\section{Results}

Comparison between the demographic data of the neonates in both groups is represented in (Table 3).

Cause of jaundice was studied among all patients. It was due to hemolytic cause in 34 (34\%) patients, 6 (17.64\%) of them were due to $\mathrm{RH}$ incompatibility, 17 (50\%) of them were due to $\mathrm{ABO}$ incompatibility, and 2 $(5.88 \%)$ of them were due to $\mathrm{ABO}+\mathrm{RH}$; other causes of hemolysis such as minor blood group incompatibilities occurred in 9 patients. Non-hemolytic causes in $66 \%$ of the cases, 29 of them were due to $\mathrm{ABO}$ incompatibility 
Table 3 Demographic data of all studied groups of neonates $(n=100)$

\begin{tabular}{|c|c|c|c|c|c|c|}
\hline & & \multicolumn{4}{|l|}{ Group } & \multirow{3}{*}{$P$ value } \\
\hline & & \multicolumn{2}{|c|}{ Patients without neurological manifestations } & \multicolumn{2}{|c|}{ Patients with neurological manifestations } & \\
\hline & & $N=50$ & $\%$ & $N=50$ & $\%$ & \\
\hline \multirow[t]{2}{*}{ Preterm or full term } & Preterm & 11 & 22.0 & 13 & 26.0 & 0.64 \\
\hline & Full term & 39 & 78.0 & 37 & 74.0 & \\
\hline \multirow[t]{2}{*}{ Single or twins } & Single & 47 & 94.0 & 50 & 100.0 & 0.242 \\
\hline & Twins & 3 & 6.0 & 0 & 0.0 & \\
\hline \multirow[t]{2}{*}{ Sex } & Male & 29 & 58.0 & 27 & 54.0 & 0.687 \\
\hline & Female & 21 & 42.0 & 23 & 46.0 & \\
\hline
\end{tabular}

$P$ value $<0.05$ is considered significant

without evidence of hemolysis in (43.93\%) and 37 of them with unknown causes (56\%) (Table 4).

The results of BIND-M score were studied which describes the characteristics of the mental state, muscle tone, cry pattern, and eye movement (Table 5).

The mean BIND score among all the studied patients was $2.15 \pm 2.75$ (Table 6).

The grade of BIND-M score among group (2) in which maximum total score for BIND-M is 12 ; a score of $1-4$ was predicted to be indicative of mild $\mathrm{ABE}$, which is generally considered to be reversible if treated promptly and aggressively which was seen in 25 patients representing $50 \%$ of the cases in group (2); and an intermediate score (5-6) was predicted to be indicative of moderate $\mathrm{ABE}$, which might be reversible with urgent and prompt bilirubin reduction which was seen in 18 patients representing $36 \%$ of the cases in group (2); and higher scores $(>7)$ would likely indicate severe/very severe $A B E$, probably representing irreversible brain damage in most infants and it was seen in seven patients representing $14 \%$ of the cases in group (2) (Table 7).

There was no statistically significant correlation between Bind score and $\mathrm{B} / \mathrm{A}$ ratio (Table 8 )

There was no statistically significant difference between the two groups as regards hemoglobin level, hematocrit, retics count, total leukocyte count, platelet count, and direct bilirubin and albumin.

There was statistically significant difference between the two groups as regards TSB and bilirubin albumin ratio (Table 9).
Neurological dysfunction using bilirubin albumin ratio in all patient is illustrated in Fig. 1.

At chosen cutoff value of bilirubin albumin ratio (B/A) 6.68 , sensitivity was $82 \%$ while specificity was $64 \%$ and accuracy was $95 \%$. This means that at a $(\mathrm{B} / \mathrm{A})$ of $<6.68$, most of the neonates had no neurological manifestations.

$P$ value less than 0.05 is considered significant.

There was statistically significant difference between the two groups as regards bilirubin albumin ratio (Table 10).

Detection of neurological dysfunction using total serum bilirubin in all patients is illustrated in Fig. 2.

At chosen cutoff value of bilirubin 28.55, sensitivity was $66 \%$ while specificity was $84 \%$ and accuracy was $95 \%$. There was no statistically significant difference between the two groups as regards total serum bilirubin (Table 11).

Detection of neurological dysfunction using albumin in all patients is illustrated in Fig. 3 and Table 12.

\section{Discussion}

Kernicterus or bilirubin encephalopathy, a preventable cause of handicap, still occurs in our community. The crash cart approach to babies with severe hyperbilirubinemia and rapid intervention with intensive phototherapy and exchange transfusion is the only known measures to prevent the occurrence of bilirubin-induced neurological damage $[8,9]$.

Measurements of albumin concentration and bilirubin/albumin $(\mathrm{B} / \mathrm{A})$ ratio may provide much more insight into the likelihood of BIND. The $\mathrm{B} / \mathrm{A}$ ratio is considered

Table 4 Types of jaundice among the studied neonates

\begin{tabular}{lll}
\hline Type & Number of cases & Subtypes \\
\hline Hemolytic cause & $34 / 100(34 \%)$ & RH incompatibility, 6/34 (17.64\%) \\
& & ABO incompatibility, 17/34 (50\%) \\
& ABO+RH, 2/34 (5.88\%) \\
Non-hemolytic cause & Others, 9/34 (26.47\%) \\
& ABO incompatibility without evidence of hemolysis, 29/66 (43.93\%) \\
\hline
\end{tabular}


Table 5 Frequency of distribution modified BIND score (BINDM) among the neonates in group (2)

\begin{tabular}{llll}
\hline & & $n=50$ & $\%$ \\
\hline Mental state & Mild & 7 & 7.0 \\
& Moderate & 40 & 40.0 \\
Muscle tone & Severe & 3 & 3.0 \\
& Normal & 50 & 50.0 \\
& Mild & 18 & 18.0 \\
Cry pattern & Moderate & 16 & 16.0 \\
& Severe & 5 & 5.0 \\
Eye movement & Normal & 61 & 61.0 \\
& Mild & 16 & 16.0 \\
& Moderate & 8 & 8.0 \\
& Severe & 1 & 1.0 \\
& Normal & 75 & 75.0 \\
& Normal & 94 & 94.0 \\
& Severe & 6 & 6.0 \\
\hline
\end{tabular}

a surrogate parameter for free bilirubin and an interesting additional parameter in the management of hyperbilirubinemia [5].

The current study included 100 newborn infants and was conducted as a prospective cohort study on neonates with hyperbilirubinemia reached critical level of phototherapy or exchange transfusion according to the American Academy of Pediatrics admitted to the NICU department, at Abuelrish pediatric Hospital, over a period of 6 months from January 2016 to June 2016 .

In our study, we found that the male to female ratio was 1.2:1. The male predominance was also noted in the group of patients with neurological manifestation with a ratio of 1.2:1.

This correlates well with the study done by [7, 22].

This also correlates well with the study done by Iskander et al. [15] who reported $68 \%$ for males and $31.4 \%$ for females, $($ male/female ratio $=1.16: 1)$.

[28] suggested that this increased susceptibility to bilirubin-induced injury in male neonates may be due to an impact of gonadotropin surge during late embryonic and early postnatal life on CNS development or innate gender-based neuronal differences independent of circulating sex steroids.

In the present study, the mean age of onset of jaundice was $2.36 \pm 1.04$ days and the mean age of neonatal ICU admission of the babies was $4.97 \pm 2.46$. In a Turkish

Table 6 Results of BIND-M score in studied neonates in group (2)

\begin{tabular}{llll}
\hline & Mean \pm standard deviation & Median & Range \\
\hline Bind score & $2.15 \pm 2.75$ & 1 & $0-11$ \\
\hline
\end{tabular}

Table 7 The grade of BIND score in group (2)

\begin{tabular}{lll}
\hline Grade of BIND score & $N=50$ & $\%$ \\
\hline Mild (1-4) & 25 & 50 \\
Moderate (5-6) & 18 & 36 \\
Severe $(>7)$ & 7 & 14 \\
\hline
\end{tabular}

study, [6] studied neonates $>35$ weeks and documented that the day the family noticed jaundice was 2.9 days $( \pm$ 1.7 SD) and the postnatal age at admission was of $4.6 \pm$ 2.3 days. Iskander et al. [15] related this late presentation to early discharge from maternity units $(<24 \mathrm{~h})$ often with no neonatal clinical examination prior to discharge, no evaluation for the risk of developing jaundice, or any instructions for follow-up, lack of available or affordable phototherapy, and false sense of security regarding the potential consequences of severe jaundice by both physicians and parents.

Signs of acute bilirubin encephalopathy (ABE) were studied in the group of patients with neurological manifestations who were representing $50 \%$ of the studied neonates on admission. The BIND score was used to assess the severity of acute bilirubin encephalopathy through examining mental state, muscle tone, and cry. Subtle ABE was found in 25 patients (50\%) with BIND score (1-4), 18 patients (36\%) had signs suggestive of moderate ABE with BIND score (5-6) while only 7 patients (14\%) showed signs suggestive of advanced ABE with BIND score $(>7)$.

In a 2-year British study by [19], they reported an incidence of $\mathrm{ABE}$ of $12 \%$ which correlates well with our results.

On the other hand, a higher percentage was found by [12], who reported $40 \%$ of their cases suffered from $A B E$ on admission and $14 \%$ still had evidence of $\mathrm{BE}$ at discharge. This higher incidence of $\mathrm{ABE}$ on admission could be explained by their inclusion criteria which required a higher admission TSB (> $25 \mathrm{mg} / \mathrm{dl}$ ) compared with our study.

Severe neonatal hyperbilirubinemia due to hemolytic causes represented $34 \%$ of our cases of which $50 \%$ and $17.64 \%$ of the cases were due to $\mathrm{ABO}$ incompatibility and $\mathrm{Rh}$ incompatibility respectively, while undiagnosed hemolytic causes represented $26.47 \%$ of the total number of cases. The latter could be attributed to minor blood group incompatibilities which are not routinely tested for. On the other hand, non-hemolytic jaundice occurred in $66 \%$ of our cases. A study by [30] documented that $21.8 \%$ of neonates with hyperbilirubinemia above $20 \mathrm{mg} /$ $\mathrm{dl}$ had ABO incompatibility, and $2.9 \%$ had Rh incompatibility in their study. The incidence of Rh incompatibility in our country is still high compared with the developed world. This is due to the defective antenatal $\mathrm{Rh}$ screening for mothers and timely provision of anti-D 
Table 8 Relation between BIND score and B/A ratio in patients with neurological manifestation

\begin{tabular}{|c|c|c|c|c|c|}
\hline & & \multicolumn{3}{|l|}{ B/A ratio } & \multirow{2}{*}{$\begin{array}{l}P \\
\text { value }\end{array}$} \\
\hline & & Mean \pm standard deviation & Median & Range & \\
\hline \multirow[t]{3}{*}{ Grade of BIND } & Mild ABE & $8.06 \pm 1.77$ & 7.79 & $5-12.5$ & \multirow[t]{3}{*}{0.092} \\
\hline & Moderate ABE & $7.99 \pm 2.54$ & 8.25 & $2.89-11.71$ & \\
\hline & Severe ABE & $10.53 \pm 2.79$ & 11.90 & $6.25-13.45$ & \\
\hline
\end{tabular}

$P$ value less than 0.05 is considered significant

antibody which is an essential component of primary prevention of Rh disease and its consequences.

In our study, 10 of 14 infants with Rh incompatibility (71.4\%) developed BE but only one (7.1\%) developed chronic bilirubin encephalopathy, 22 of $46(47.8 \%)$ infants with $\mathrm{ABO}$ hemolytic disease developed $\mathrm{BE}$ but only $2(4.3 \%)$ developed kernicterus. On the other hand, 21 of $66(31.8 \%)$ infants with non-hemolytic jaundice developed BE but only 3of 66 (4.5\%) developed kernicterus.

This suggests that hemolysis is a risk factor for the occurrence of acute bilirubin encephalopathy and that timely intervention may stop the progression to chronic bilirubin encephalopathy and is in agreement with the risk factors defined by the AAP guidelines in 2004 [30]. also reported that kernicterus was more common in neonates with blood group incompatibility compared with other causes of jaundice.

In our study, the risk factors in cases in order were prematurity in 24 newborns (24\%), ABO incompatibility in 46 newborns (46\%), RH incompatibility in 14 newborns (14\%), infants of diabetic mothers in 2 newborns $(2 \%)$, and history of neonatal jaundice in previous babies in 15 newborns (15\%).

In a study by Zabeen et al., [31] on 60 jaundiced newborn infants in a tertiary hospital to detect different risk factors for neonatal jaundice, they found that prematurity, IDM, septicemia, and ABO incompatibility were observed in 44 (73.3\%), 21 (35\%), 16 (26.6\%), and 8 (13.3\%) cases respectively. G6PD deficiency was found in only one (1.7\%) case. They agree with our study in that prematurity was the risk for neonatal jaundice in most cases and G6PD deficiency was the least risk factor.

In the present study, the mean peak TSB level in all cases was $26.14 \pm 7.36 \mathrm{mg} / \mathrm{dl}$. A statistically significant difference was found between the mean peak TSB level in the patients with neurological manifestations (29.24 \pm $7.78 \mathrm{mg} / \mathrm{dl}$ ) and the mean peak TSB level in the patients without neurological manifestations was $(23.04 \pm 5.41$ $\mathrm{mg} / \mathrm{dl})$.

The total serum bilirubin level in patients on admission without neurological manifestations on admission $(22.8 \mathrm{mg} / \mathrm{dl})$ was lower than the median TSB level for patients with neurological manifestations which was 30 $\mathrm{mg} / \mathrm{dl}$.

Although the TSB was higher in the group 2, higher bilirubin levels were recorded in those with moderate $\mathrm{ABE}$ than those with severe $\mathrm{ABE}$. This question whether TSB can be relied upon as an independent prognostic factor for poor neurological outcome.

Gamaleldin study 2011 reported that out of 106 infants who were disease free, $26 \%$ had a TSB level of > $31.5 \mathrm{mg} / \mathrm{dl}$ and the lowest bilirubin level at which kernicterus occurred was $25 \mathrm{~m} / \mathrm{dl}$ [18]. also showed that all kernicteric babies in their study had TSB levels $>30 \mathrm{mg} /$

Table 9 Comparison between the two groups regarding laboratory investigations done

\begin{tabular}{|c|c|c|c|c|c|c|c|}
\hline & \multicolumn{6}{|l|}{ Group } & \multirow{3}{*}{$P$ value } \\
\hline & \multicolumn{3}{|l|}{$\begin{array}{l}\text { Group } 1 \\
N=50\end{array}$} & \multicolumn{3}{|l|}{$\begin{array}{l}\text { Group } 2 \\
N=50\end{array}$} & \\
\hline & Mean \pm SD & Median & Range & Mean \pm SD & Median & Range & \\
\hline $\mathrm{HB}(\mathrm{g} / \mathrm{dl})$ & $12.72 \pm 2.99$ & 12.77 & $4-18.7$ & $12.84 \pm 3.23$ & 12.15 & $6.50-19.6$ & 0.978 \\
\hline $\mathrm{HCt}(\%)$ & $37.25 \pm 7.76$ & 37.45 & $12-51.9$ & $36.13 \pm 10.15$ & 35.25 & $0.90-55.7$ & 0.408 \\
\hline Retics (\%) & $5.11 \pm 9.86$ & 2.15 & $0.0-65$ & $5.43 \pm 5.40$ & 3.1 & $0.0-20.8$ & 0.544 \\
\hline $\operatorname{TLC}\left(10^{3} / \mathrm{mm}^{3}\right)$ & $7.15 \pm 1.51$ & 7.1 & $3.1-10.8$ & $7.12 \pm 0.87$ & 7.1 & $5.3-9.1$ & 0.920 \\
\hline PLt $\left(10^{3} / \mathrm{mm}^{3}\right)$ & $284.3 \pm 70.55$ & 310 & $160-420$ & $297.84 \pm 68.59$ & 308.5 & $183-423$ & 0.440 \\
\hline T. Bil & $23.04 \pm 5.41$ & 22.8 & $12.30-33$ & $29.24 \pm 7.78$ & 30 & $8.1-46.5$ & $<0.001$ \\
\hline D. Bil & $1.13 \pm 0.83$ & 1 & $0.1-5$ & $1.73 \pm 1.70$ & 1.1 & $0.1-9$ & 0.1 \\
\hline Alb & $3.63 \pm 0.55$ & 3.7 & $2-4.7$ & $3.54 \pm 0.70$ & 3.55 & $2-5$ & 0.389 \\
\hline $\mathrm{B} / \mathrm{A}$ ratio & $6.46 \pm 1.84$ & 6.09 & $3.85-14$ & $8.38 \pm 2.34$ & 8.08 & $2.89-13.45$ & $<0.001$ \\
\hline
\end{tabular}

$P$ value less than 0.05 is considered significant 


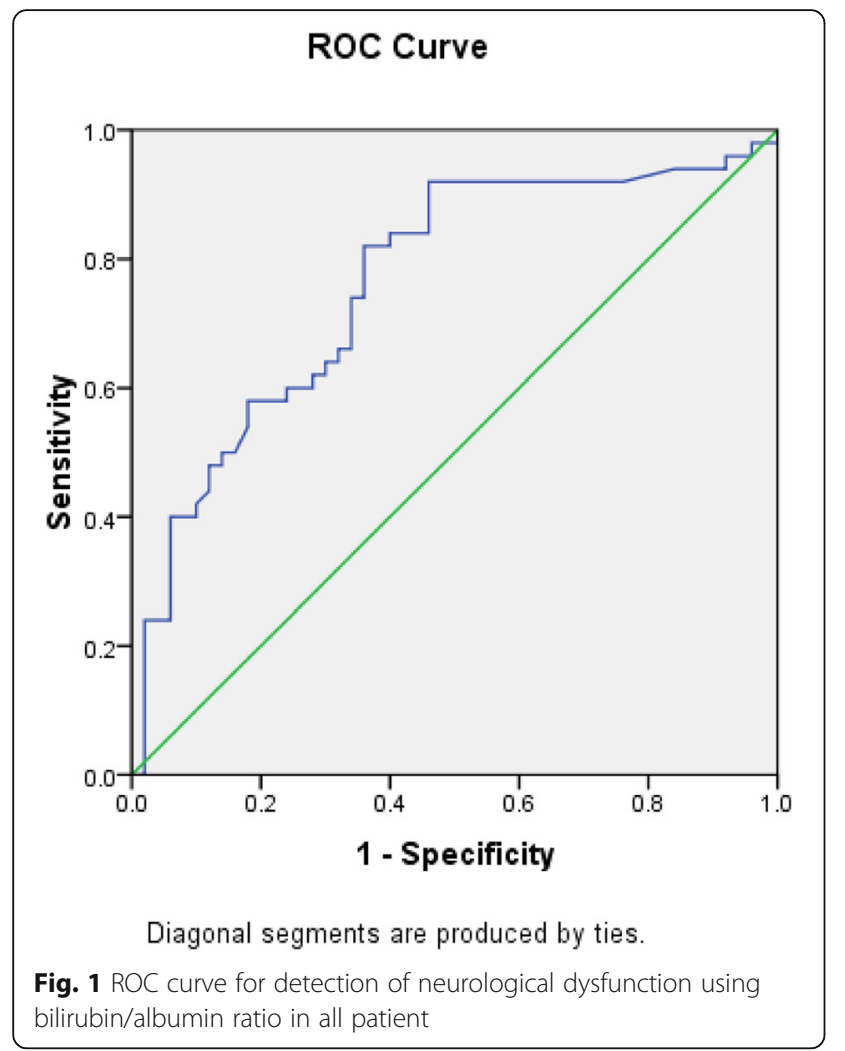

dl. These findings prompt us to agree with [17] that in the absence of risk factors i.e. in healthy full-term neonates, such levels are detected (serum bilirubin less than $30 \mathrm{mg} \%$ ).

[25] reported that subtle neurotoxicity may appear later or even at school age as learning disabilities. This could be important in making long-term follow-up a necessity.

It is clear from the previous results that there exists a wide variation in the individual response to TSB which indicates that though serum bilirubin is sensitive, yet it is not specific in many cases. This also indicates that the pathogenesis of $\mathrm{BE}$ involves critical plasma and/or host defense variables that have yet to be identified.

Free bilirubin and not TSB is the principal determinant of bilirubin neurotoxicity. There is presently no method available for measuring free bilirubin concentrations accurately in plasma or serum so the bilirubin albumin ratio $(\mathrm{B} / \mathrm{A})$ is considered as a surrogate parameter for free bilirubin and an additional parameter in the prediction of $\mathrm{BE}$ [13].
The mean $\mathrm{B} / \mathrm{A}$ ratio among the neonates with neurological manifestations was $(8.38 \pm 2.34)$, whereas among the jaundiced neonates without neurological manifestations was $(6.46 \pm 1.84)$ and this difference was statistically significant.

[2] reported that the mean $\mathrm{B} / \mathrm{A}$ ratio among patients with $\mathrm{BE}$ was $(10 \pm 1.6)$, whereas among other jaundiced neonates was $(6.1 \pm 2.4)$. They also reported that neurotoxicity does not occur until the molar concentration of bilirubin approached the concentration of albumin (B/A ratio $=8.8$ ). As TSB exceeds this binding capacity, free bilirubin increases dramatically and the final deposition is governed by the availability of alternative plasma binding loci and ultimately by the low solubility of free bilirubin.

All babies with B/A ratio > 13.1 developed BIND. However, we observed one baby with normal outcomes at $\mathrm{B} / \mathrm{A}$ ratio of $12.5 \mathrm{mg} / \mathrm{g}$. This suggests that additional bilirubin binding sites other than albumin must exist in plasma.

Receiver operating characteristics (ROC) analysis identified $\mathrm{B} / \mathrm{A}$ ratio cutoff value for predicting bilirubininduced neurological dysfunction was 6.68 (AUC 0.76) with sensitivity of $82 \%$ and specificity of $64 \%$ and these results were statistically significant, whereas TSB cutoff value of $28.55 \mathrm{mg} / \mathrm{dl}$ showed sensitivity of $66 \%$ and specificity of $84 \%$ and these results were statistically significant [2]. identified B/A cutoff value for predicting acute BIND of 8 (AUC 0.957 ) with sensitivity of $100 \%$ and specificity of $94 \%$, whereas a TSB cutoff value of $25 \mathrm{mg} / \mathrm{dl}$ in their study showed sensitivity of $100 \%$ and specificity of $85 \%$. According to this finding, B/A ratio was more specific than TSB in the prediction of poor neurological outcome. Variations in the expanded buffering capacity combined with variation in blood-brain barrier function and host defenses at the cellular level provide the only explanation for the limited specificities of TSB and B/A in predicting outcome.

Until now, the precise threshold at which TSB or bilirubin albumin ratio may be neurotoxic in a given infant is unknown. We therefore agree with [16] that it is very important to study and identify the individual differences in the ability to destroy bilirubin in the brain and the factors that expedite or delay its neuronal exit which may help identify the baby prone to neuronal damage and therefore aid in the prevention of kernicterus.

Table 10 AUC, cutoff value, sensitivity, and specificity of B/A ratio for detection of neurological dysfunction

\begin{tabular}{lllllll}
$\begin{array}{l}\text { Area } \\
\text { under } \\
\text { curve }\end{array}$ & $P$ value & 95\% confidence interval & & $\begin{array}{l}\text { Cutoff } \\
\text { value }\end{array}$ & $\begin{array}{l}\text { Sensitivity } \\
(\%)\end{array}$ & $\begin{array}{l}\text { Specificity } \\
(\%)\end{array}$ \\
\cline { 2 - 6 } & & Lower bound & Upper bound & & 82 & 64 \\
\hline .763 & $<0.001$ & .667 & .858 & 6866 & 64 \\
\hline
\end{tabular}

AUC (area under the curve) $=0.763 ; P$ value less than 0.05 is considered significant 


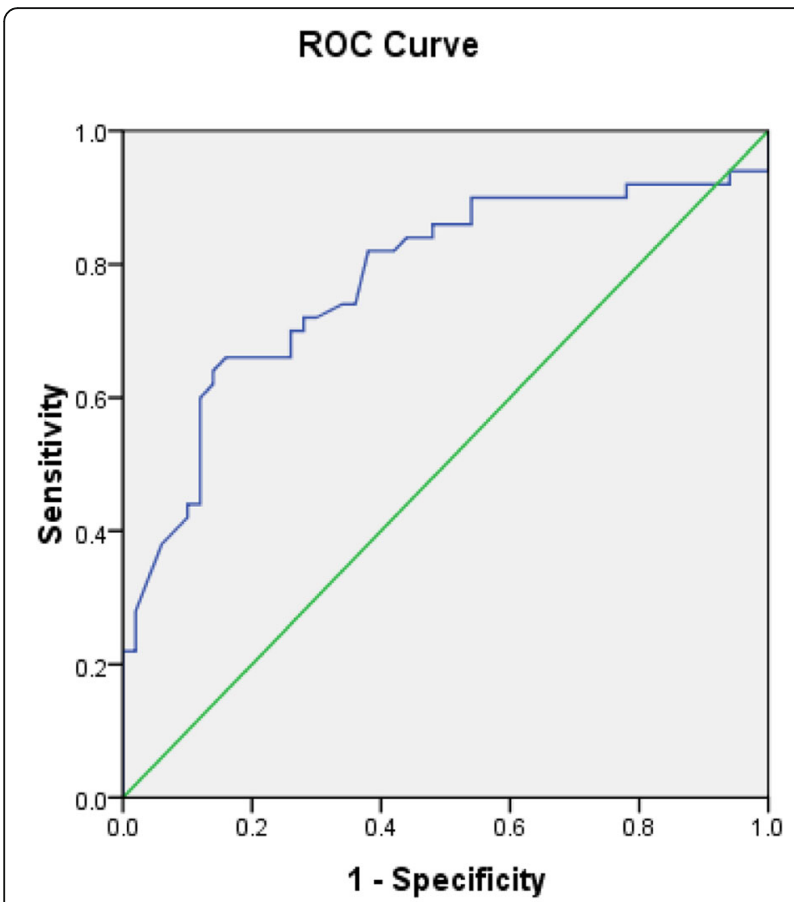

Diagonal segments are produced by ties.

Fig. 2 ROC curve for detection of neurological dysfunction using total serum bilirubin in all patients

Among the group of patients with neurological manifestations showed a male predominance (54\%), nine (33\%) of them had ABO incompatibility, seven of them (25\%) had RH incompatibility, none of them had sepsis, and 13 had jaundice of unknown cause. The TSB and $\mathrm{B} / \mathrm{A}$ ratio were significantly higher in all the patients with neurological manifestations. All received intensive phototherapy in the Bilisphere and all had exchange transfusions.

\section{Limitations of the study}

1. Our study included $74 \%$ of the patients were full-term babies and $26 \%$ of them were preterm babies which gave no chance to accurately test the predictive value of bilirubin/albumin ratio for early detection of neurological dysfunctions in the preterm babies.

2. The number of cases and duration along which our cases were collected in our study were limited, so

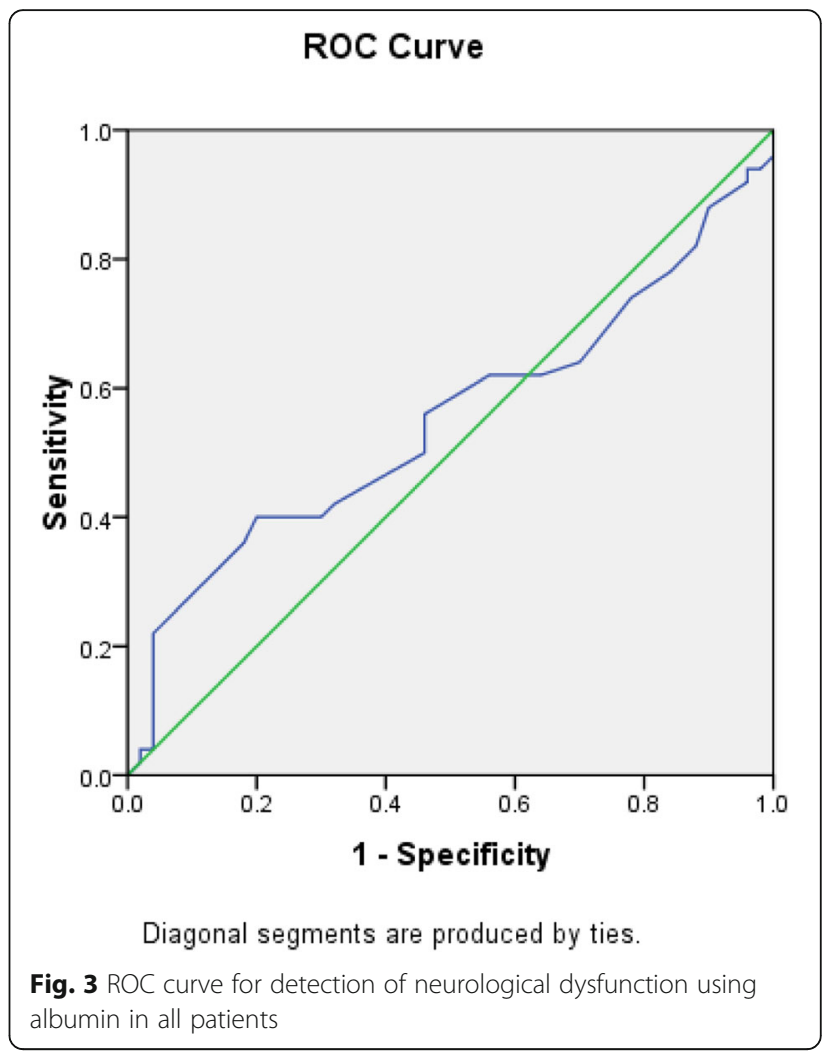

further studies needed on a larger sample size and on a longer duration to confirm our results.

3. Varity and overlapping of the etiological risk factors as $\mathrm{ABO}, \mathrm{Rh}$ incompatibility, and sepsis.

4. Inability to do routine G6PD enzyme assay and large category of unknown causes (37\% of cases).

\section{Conclusions}

- Kernicterus is a preventable cause for brain injury resulting from severe untreated neonatal hyperbilirubinemia.

- There is a high prevalence of severe hyperbilirubinemia and kernicterus in the NICU of CUPH.

- The most frequent causes of severe hyperbilirubinemia in our population are $\mathrm{ABO}$ incompatibility and $\mathrm{Rh}$ incompatibility. Undetermined causes are still present in a big number of cases.

Table 11 AUC, cutoff value, sensitivity, and specificity of total serum bilirubin for detection of neurological dysfunction

\begin{tabular}{|c|c|c|c|c|c|c|}
\hline \multirow{2}{*}{$\begin{array}{l}\text { Area } \\
\text { under } \\
\text { curve }\end{array}$} & \multirow[t]{2}{*}{$P$ value } & \multicolumn{2}{|c|}{ 95\% confidence interval } & \multirow{2}{*}{$\begin{array}{l}\text { Cutoff } \\
\text { value }\end{array}$} & \multirow{2}{*}{$\begin{array}{l}\text { Sensitivity } \\
(\%)\end{array}$} & \multirow{2}{*}{$\begin{array}{l}\text { Specificity } \\
(\%)\end{array}$} \\
\hline & & Lower bound & Upper bound & & & \\
\hline .776 & $<0.001$ & .681 & .870 & 28.55 & 66 & 84 \\
\hline
\end{tabular}

AUC (area under the curve) $=0.776 ; P$ value less than 0.05 is considered significant 
Table 12 AUC and $P$ value for albumin for detection of neurological dysfunction

\begin{tabular}{llll}
\hline Area & $P$ & \multicolumn{2}{l}{ 95\% confidence interval } \\
\cline { 3 - 4 } $\begin{array}{l}\text { under } \\
\text { curve }\end{array}$ & value & Lower bound & Upper bound \\
\hline .550 & .391 & .434 & .665 \\
\hline
\end{tabular}

$P$ value less than 0.05 is considered significant

- Total serum bilirubin was sensitive but not specific to neurologic affection.

- Estimation of B/A ratio proved to be a more specific indicator of the neurologic outcome of neonates with severe hyperbilirubinemia.

\section{Abbreviations}

ABE: Acute bilirubin encephalopathy; B/A ratio: Bilirubin/albumin ratio; BE: Bilirubin encephalopathy; Bf: Free bilirubin; BIND: Bilirubin-induced neurologic dysfunction; CBC: Complete blood count; CUPH: Children University Pediatric Hospital; DSB: Direct serum bilirubin; RH: Rhesus; TCB: Transcutaneous bilirubin; TSB: Total serum bilirubin; UCB: Unconjugated bilirubin

\section{Acknowledgements}

I would also like to thank the whole members of the NICU department at Abuelrish Pediatric Hospital for their true support and help.

\section{Authors' contributions}

All authors reviewed the final version of the manuscript, believe it represents valid work, and approve it for publication. As an Author, I certify that none of the material in the Article has been published. RS and DM contributed to the study conception and design. NA, ME, and DM contributed to data acquisition. ME, NA, DM, and RS contributed analysis and data interpretation. DM and RS contributed to drafting of the manuscript. RS and DM contributed to critical revision.

\section{Funding}

The authors have no financial relationships relevant to this article to disclose.

\section{Availability of data and materials}

The corresponding author had full access to all of the data and takes full responsibility for the veracity of the data and statistical analysis.

\section{Ethics approval and consent to participate}

The trial was based on Master of Science thesis approved by Pediatric Department Committee for Post-Graduate Studies and Research, and by Post-Graduate Studies and Research administration, Faculty of Medicine, Cairo University, Egypt. Approval date was 21/12/2015.

Written consents were obtained from parents of study participants. Investigations and all lines of treatments were clarified.

\section{Consent for publication}

Written consents were obtained from parents of study participants. Investigations and all lines of treatments were clarified. Consents included agreement for publication.

\section{Competing interests}

The authors declare that they have no competing interests.

Received: 12 July 2019 Accepted: 1 November 2019

Published online: 02 December 2019

\section{References}

1. American Academy of Pediatrics (2004) Practice parameter: management of hyperbilirubinemia in the healthy term newborn. Pediatrics 94(4):558-565

2. Ardakani SB, Dana VG, Ziaee V, Ashtiani M-TH, Djavid GE, Alijani M (2011) Bilirubin/albumin ratio for predicting acute bilirubin-induced neurologic dysfunction. Iran J Pediatr 21(1):28
3. Arenas Rueda YA, Arenas GLP (2015) Intravenous immunoglobulin as an option to treat newborn jaundice caused by ABO incompatibility. Medicas UIS 28(1):91-97

4. Arenas Rueda YA, Arenas GLP (2015) Intravenous immunoglobulin as an option to treat newborn jaundice caused by $A B O$ incompatibility. Medicas UIS 28(1):91-97.

5. Behjati $S$ et al (2011) Bilirubin/albumin ratio for predicting acute bilirubininduced neurologic dysfunction. Iran J Pediatr 21(1):28-32

6. Bulbul A, Okan FF, Unsur EK, Nuhoglu A (2011) Adverse events associated with exchange transfusion and etiology of severe hyperbilirubinemia in near-term and term newborns. Turk J Med Sci. 41:93-100

7. Burke BL, Robbins JM, Bird TM, Hobbs CA, Nesmith C, Tilford JM (2009) Trends in hospitalizations for neonatal jaundice and kernicterus in the United States, 1988-2005. Pediatrics 123:524-532

8. Ballot DE, Rugamba G (2016) Exchange transfusion for neonatal hyperbilirubinemia in Johannesburg, South Africa, from 2006 to 2011. Int Scholarly Res Notices 2016(2016)

9. Bujandric N, Grujic J (2016) Exchange transfusion for severe neonatal hyperbilirubinemia: 17 years' experience from Vojvodina, Serbia. Indian J Hematol Blood Transfus 32(2):208-214

10. Bofarraj MAM, Ajlail MJ (2015) Evaluation of pattern and risk factors of indirect neonatal hyperbilirubinemia at Benghazi Children Hospital in 2013. Egypt J Pediatr 32(2015):291-305

11. Daood MJ, McDonough AF, Watchko JF (2009) Calculated free bilirubin levels and neurotoxicity. J Perinatol 29(Suppl 1):S14-S19

12. Gamaleldin R, Iskander I, Seoud I, Aboraya H, Aravkin A, Sampson P, Wennberg R (2011) Risk factors for neurotoxicity in newborns with severe neonatal hyperbilirubinemia. Pediatrics 128(4):e925-e931

13. Hulzebos CV, Van Imhoff DE, Bos AF, Ahlfors CE, Verkade HJ, Dijk PH (2008) Usefulness of the bilirubin/albumin ratio for predicting bilirubin-induced neurotoxicity in premature infants. Arch Dis Child Fetal Neonatal Ed 93(5): F384-F388

14. Hulzebos CV, Dijk PH (2014) Bilirubin-albumin binding, bilirubin/albumin ratios, and free bilirubin levels: where do we stand? Semin Perinatol 38(7) WB Saunders, 2014

15. Iskander I, Gamaleldin R, El Houchi S, El Shenawy A, Seoud I, El Gharbawi N, Abou-Youssef H, Aravkin A, Wennberg RP (2014) Serum bilirubin and bilirubin/albumin ratio as predictors of bilirubin encephalopathy. Pediatrics 134(5):e1330-e1339

16. Johnson L, Bhutani VK (2011) The clinical syndrome of bilirubin-induced neurologic dysfunction. Semin Perinatol 35(3):101-113

17. Maisels MJ, Newman TB (2006) Surveillance of severe neonatal hyperbilirubinemia: a view from south of the border. CMAJ 175(6):599

18. Mukhopadhyay K, Chowdhary G, Singh P, Kumar P, Narang A (2010) Neurodevelopmental outcome of acute bilirubin encephalopathy. J Trop Pediatr 56(5):333-336

19. Manning D, Todd P, Maxwell M, Platt MJ (2007) Prospective surveillance study of severe hyperbilirubinemia in the newborn in the UK and Ireland. Arch Dis Child Fetal Neonatal Ed. 92:342-346

20. Olusanya BO, Osibanjo FB, Mabogunje CA, Slusher TM, Olowe SA (2016a) The burden and management of neonatal jaundice in Nigeria: a scoping review of the literature. Niger J Clin Pract 19(1):1-17

21. Olusanya BO, Imam ZO, Emokpae AA, Iskander IF (2016b) Revisiting the criteria for exchange transfusion for severe neonatal hyperbilirubinemia in resource-limited settings. Neonatology 109(2):97-104

22. Paul T et al (2010) Phototherapy in different stages of birth weight for the treatment of neonatal hyperbilirubinaemia. J Bio Sci 18(2010):116-120

23. Radmacher PG et al (2015) A modified Bilirubin-induced neurologic dysfunction (BIND-M) algorithm is useful in evaluating severity of jaundice in a resource-limited setting. BMC Pediatr 15(1):28

24. Riodan M (2016). A hypothesis for using pathway genetic load analysis for understanding complex outcomes in bilirubin encepalopathy. Frontiers in neuroscience 10(2016)

25. Shapiro SM (2010) Chronic bilirubin encephalopathy: diagnosis and outcome. Semin Fetal Neonatal Med 15(3):157-163

26. Shetty A and Binoop S. (2014). A study of neonatal hyperbilirubinemia in tertary care hospital. International Journal of Medical Science and Public Health 3.10(2014):1289-93.

27. Slim G, Naous A, Naja Z, Naja AS, Rajab M (2015) Effect of instituting a hospital pre-discharge bilirubin screening on subsequent significant hyperbilirubinemia in term and near term newborn 
28. Watchko JF (2010) Hyperbilirubinemia in African American neonates: clinical issues and current challenges. Semin Fetal Neonatal Med. 15:176-182

29. Watchko JF, Maisels MJ (2014) The enigma of low bilirubin kernicterus in premature infants: why does it still occur, and is it preventable? Semin Perinatol 38(7):397-406

30. Weng YH, Chiu YW (2009) Spectrum and outcome analysis of marked neonatal hyperbilirubinemia with blood group incompatibility. Chang Gung Med J 32(4):400-408

31. Zabeen B, Jebun N, Nabi N, Baki A, Tayyeb S, Azad K, Nahar N (2010) Risk factors and outcome of neonatal jaundice in a tertiary hospital. Ibrahim Med Coll J 4(2):70-73

\section{Publisher's Note}

Springer Nature remains neutral with regard to jurisdictional claims in published maps and institutional affiliations.

\section{Submit your manuscript to a SpringerOpen ${ }^{\circ}$ journal and benefit from:}

- Convenient online submission

- Rigorous peer review

- Open access: articles freely available online

- High visibility within the field

- Retaining the copyright to your article

Submit your next manuscript at $\boldsymbol{\nabla}$ springeropen.com 